\title{
KAJIAN INOVASI DESAIN BIOSKOP DALAM UPAYA PENGEMBALIAN MINAT GENERASI MILENIAL TERHADAP MOTION PICTURE ENTERTAINMENT
}

\author{
Chelsea Mutama ${ }^{1)}$, Nina Carina ${ }^{2)}$ \\ 1) Program Studi S1 Arsitektur, Fakultas Teknik, Universitas Tarumanagara, chelmt97@gmail.com \\ 2) Program Studi S1 Arsitektur, Fakultas Teknik, Universitas Tarumanagara, nincarin@gmail.com
}

\begin{abstract}
Abstrak
Generasi Milenial atau Gen $Y$ adalah mereka yang lahir antar tahun 1981-2000. Perbedaan karakteristik dan gaya hidup mereka dengan generasi-generasi sebelumnya menimbulkan berbagai permasalahan dan trend baru, salah satunya adalah fenomena The Death of Cinemas yang ditandai 2 hal utama, yaitu penutupan beberapa bioskop dan penurunan pedapatan bioskop dari penjualan tiket. Sejak dampak dari fenomena ini semakin terasa, 2 perusahaan yang bergerak di bidang marketing \& management bioskop melakukan riset untuk memahami penyebab peristiwa ini dan cara menanganinya. Berdasarkan hasil riset National Cinemedia (NCM) berjudul Millennials Movie Going Experience, yang dilakukan tahun 2016 mengenai penyebab fenomena The Death of Cinemas, diketahui bahwa mayoritas mengalami ketidakpuasan akan movie theater venue yang tidak mengalami perkembangan signifikan dalam 20 tahun terakhir, namun diiringi dengan kenaikan harga tiket hingga dua kali lipat. Film memiliki signifikansi besar dalam dunia generasi milenial, tidak hanya sebagai hiburan, tapi juga sarana edukasi, influencer, dan passion. Jadi, proyek ini bertujuan mengembalikan esensi dari motion picture entertainment bagi generasi milenial dan mendukung perkembangan animasi, sebagai genre film yang mengalami peningkatan pesat sebagai preferensi. Metode yang digunakan dalam perancangan adalah metode tipologi. Dengan mempelajari perkembangan movie theater venue, perancang berharap dapat memahami faktor-faktor yang berubah atau dipertahankan seiring perkembangan zaman, agar dapat menghasilkan sebuah inovasi desain yang dapat merespon movie-going behaviours dari generasi milenial dengan sebaik mungkin.
\end{abstract}

Kata kunci : bioskop; esensi; fenomena; milenial; preferensi

\begin{abstract}
The Millennials Generation or Gen Y, are those born between the year of 1981-2000. The characteristic and lifestyle differences between them and previous generations have resulted in the emergence of new problems and trends in the millennial era, including a phenomena known as The Death of Cinemas that affected the closing of some cinema venues and the drop of cinema ticket sales. According Research conducted by National Cinemedia in the year 2016, The Death of Cinemas is caused by millennials' dissatisfaction of movie theater venues. There had been no significant changes in the last 20 years while the ticket price had increased 2 times as expensive. This further resulted in $2 \%$ decrease of ticket sales per year. Other results showed that movies have a great significance on millennials, not only as entertainment, but also education, influencer, even passion. So this project, titled CineFlicks : Movie Theater \& Animation Course aims to restore the essence of motion picture entertainment for millennials and support the advancement of animation, as one of the most preferred movie genre for millennials. The design method used in this project is typology. By studying the evolution of types and variations of movie theater, the designer hopes to understand the design aspects that have changed and those that have always been maintained in movie theater planning. By doing this, the designer hopes to create a certain innovation that will able to respond millennials' movie-going behaviors as well as possible.
\end{abstract}

Keywords : cinema; essence; millennial; phenomena; preferred 


\section{PENDAhULUAN}

\section{Latar Belakang}

Kata CineFlicks pada judul proyek diambil dari 2 kata, yaitu Cinema, istilah picture entertainment yang digunakan sekarang; dan Flicks, yaitu istilah sejenis yang digunakan pada tahun 1800-an, saat awal terbentuknya motion picture. Cinema diambil dari bahasa Yunani kinema atau kinematos yang berarti pergerakan. Istilah ini mulai dipakai di akhir abad 19. Singkatnya, pada tahun 1800 -an, picture entertainment memiliki sistem yang sama seperti $2 D$ Animation, dimana sekumpulan gambar ditumpuk dan diganti secara cepat sehingga mata manusia menangkapnya sebagai gerakan (ilusi optik). Namun, pada tahun 1894, Lumiere Brothers dari Prancis merilis film berjudul Workers Leaving the Lumière Factory yang kemudian dianggap sebagai motion picture pertama dalam sejarah. Peristiwa ini menandai dimulainya era silent film. Karena teknologi masa itu belum mampu melengkapi video dengan audio, pertunjukan film biasanya diiringi musik orkestra dan reaksi karakter disampaikan ke audience dalam bentuk tulisan.

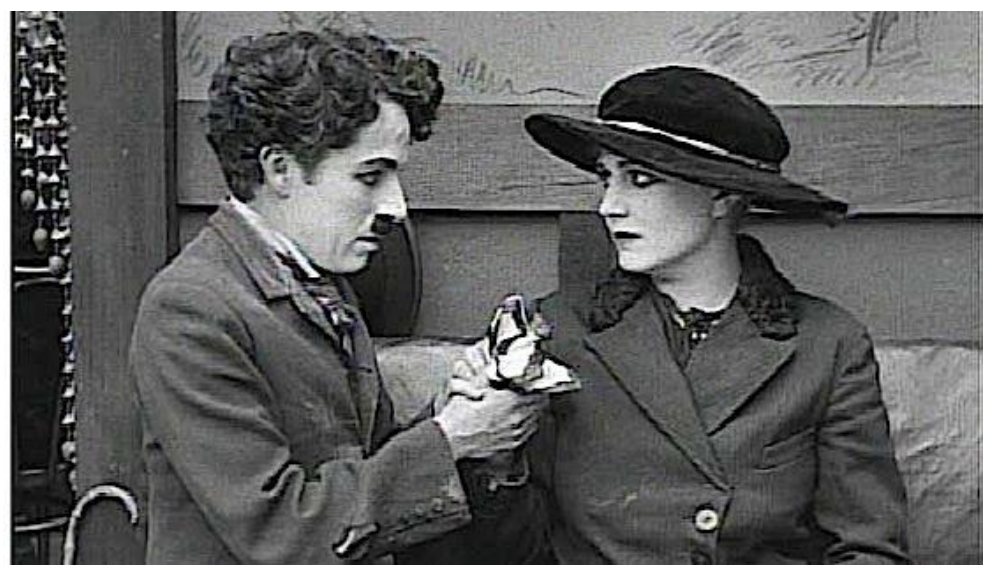

Gambar 1. Silent Film Era

Sumber: www.wikipedia.com

Sementara flicks atau flicker muncul di awal tahun 1800-an pada era magic lantern show (bentuk terawal dari motion picture entertainment), dimana showman menampilkan gambargambar statis dengan proyektor yang menggunakan cahaya dari arc lamp sambil menarasikan cerita. Arc lamp digunakan dengan mengalirkan tegangan listrik berbeda pada 2 batang karbon sehingga pertemuan batang karbon tersebut menghasilkan cahaya. Namun, cahayanya sangat tidak stabil sehingga sering berkedip saat pertunjukan. Oleh karena itu, orang-orang mulai menyebut hiburan ini flicks atau flickers.

Jadi, kata CineFlicks adalah kombinasi dari 2 istilah yang mendeskripsikan motion picture entertainment dari 200 tahun yang berbeda. Kombinasi 2 istilah ini menggambarkan esensi utama dari proyek yang bersangkutan. Saat awal terbentuknya motion picture pada tahun 1800-an, audience mendapatkan cinematic experience yang benar-benar istimewa dan belum pernah mereka jumpai sebelumnya. Namun, tingginya ekspektasi generasi millennial yang didukung oleh perkembangan teknologi mengakibatkan timbulnya trend dan masalah baru di millennial era ini, salah satunya adalah fenomena yang dikenal dengan The Death of Cinemas. Sebagai subyek dengan persentase frequent movie-goers tertinggi (38\%), generasi millennial memberikan kontribusi terbesar dalam timbulnya fenomena ini.

Singkatnya, timbulnya fenomena ini merupakan bukti bahwa cinema yang ada sekarang tidak lagi memberikan experience yang demikian untuk generasi milenial. Kombinasi kata "cinema" dan "flicks" pada judul proyek menggambarkan bahwa dalam proyek ini, perancang ingin memanfaatkan inovasi-inovasi baru di bidang arsitektur dan teknologi modern untuk mengembalikan esensi dari motion picture entertainment yang ada 200 tahun lalu, namun telah memudar di millennial era ini. 


\section{Identifikasi Masalah}

Fenomena The Death of Cinemas dimulai 20 tahun yang lalu dan ditandai dengan penurunan income bioskop dari penjualan tiket yang mencapai rata-rata $2 \%$ per tahun, dengan penurunan paling signifikan terjadi di peralihan tahun 2016-2017 setinggi 6\%. (sumber : Motion Picture Association of America). Hal ini berdampak pada kenaikan harga tiket pada tahun 2017 setinggi 3.7\% dibandingkan 2016 (sumber : National Association of Theatre Owners atau NATO). Namun, solusi ini terbukti tidak menyelesaikan masalah. Kenaikan harga tiket menjadikan masyarakat lebih selektif dalam memilih film untuk disaksikan di layar besar. Lebih jauhnya, The Death of Cinemas telah mengakibatkan beberapa bioskop kecil tutup, baik di luar negeri maupun di Indonesia.

Pada tahun 2007, berbagai bidang industri mulai menyadari dampak yang dapat terjadi jika penurunan popularitas bioskop terus berlangsung. Semakin sedikit orang yang ingin nonton di bioskop berarti semakin sedikit orang yang mau keluar rumah, semakin sedikit orang yang makan di restoran, dan semakin sedikit orang yang belanja di department store. Untuk menanggapi fenomena ini, National CineMedia U.S. atau NCM (perusahaan pemasaran bioskop asal Amerika Serikat) melakukan penelitian berjudul "Millennials Movie-Going Research 2016," yang bertujuan menganalisa habit dan behaviour generasi millennial dalam aktivitas penggunaan hiburan bioskop. Selain itu, Movio (perusahaan software yang bergerak di bidang analisa data dan manajemen serta marketing bioskop) juga melakukan riset sejenis berjudul "Understanding Millennials Movie-Goers 2015," yang membahas preferensi genre film yang ditonton oleh generasi millennial di bioskop.

Penyebab fenomena The Death of Cinemas berdasarkan hasil riset antara lain : 56\% populasi millennial tidak puas dengan fasilitas bioskop yang tersedia, $10.8 \%$ populasi millennial memprioritaskan pekerjaan (pressured dan achieving), dan $33.2 \%$ populasi millennial menganggap harga bioskop tidak ekonomis. Dari riset tersebut juga diketahui bahwa film memiliki signifikansi besar dalam dunia entertainment generasi milenial, tidak hanya sebagai hiburan, tapi juga sarana edukasi, influencer, dan passion. Aktivitas menonton juga merupakan bagian yang besar dalam millennials social activities.

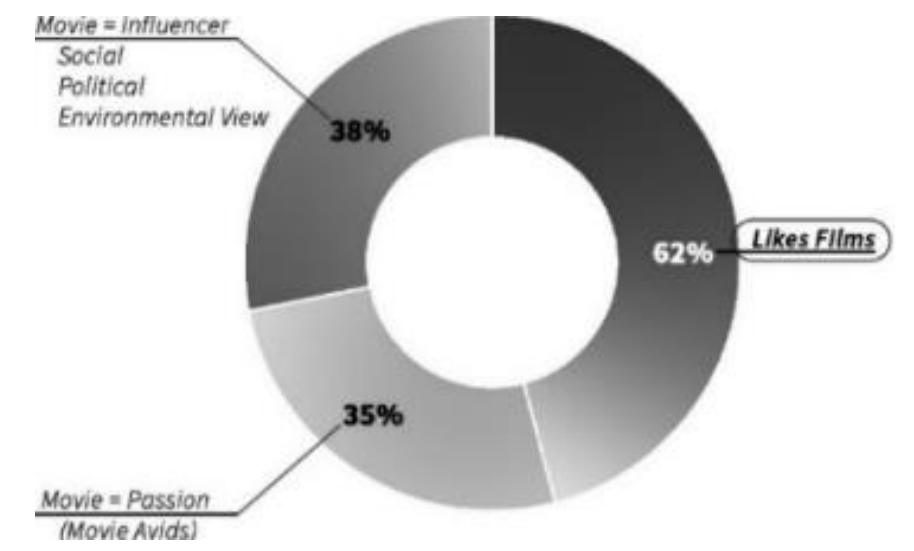

Gambar 2. Diagram Signifikansi Film bagi Generasi Milenial Sumber: Diolah oleh Penulis berdasarkan NCM, 2016

Hasil kedua dari riset NCM tergambar dalam diagram diatas menginformasikan bahwa generasi milenial umumnya tidak mau ketinggalan trend yang sedang berlangsung. Menonton film di rumah mengharuskan mereka untuk menunggu 2-3 bulan setelah film yang bersangkutan dapat disaksikan. Oleh karena itu, kebanyakan generasi milenial menyaksikan film langsung di bioksop untuk dapat mendiskusikannya dengan kelompok pergaulan mereka masing-masing. 


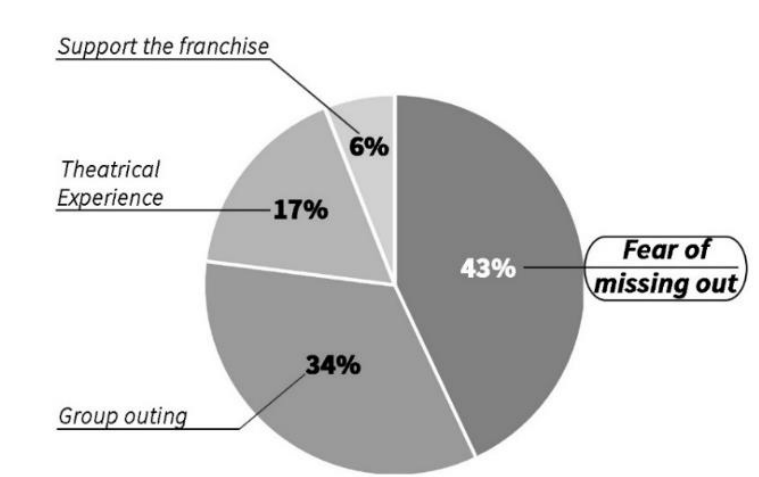

Gambar 3. Diagram Motivasi Generasi Milenial Menonton Film di Bioskop

Sumber: Diolah oleh Penulis berdasarkan NCM, 2016

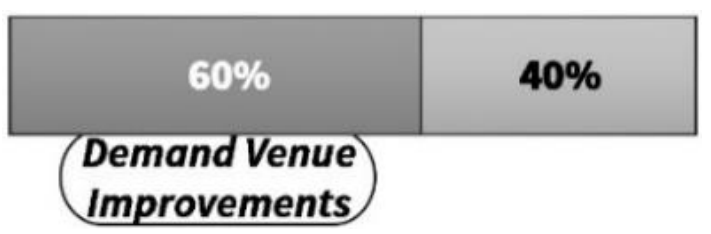

Gambar 4. Diagram Ekspektasi Generasi Milenial terhadap Peningkatan Venue Sumber: Diolah oleh Penulis berdasarkan NCM, 2016

Riset NCM juga membuktikan bahwa ketidakpuasan generasi milenial terhadap movie theater venue yang ada terutama dari segi theatrical experience yang tidak mengalami perkembangan signifikan dalam 20 tahun terakhir, namun diiringi dengan kenaikan harga tiket hingga 2 kali lipat.

Data-data dan analisa diatas yang merupakan hasil dari riset NCM "Millennials Movie Going Experience" adalah alasan perencanaan proyek Movie Theater. Kesimpulannya, generasi millennial adalah generasi dengan persentase tertinggi sebagai frequent cinema-goers. Film dan bioskop memiliki signifikansi besar bagi generasi millennial. Namun, sebagai generasi yang sangat mementingkan experience, dominan generasi millennial menuntut adanya sebuah inovasi baru dalam movie theater venue, terutama untuk memberikan theatrical experience yang sesungguhnya adalah tujuan utama dari hiburan bioskop. Movie Theater yang akan didesain adalah program utama dari proyek yang bersangkutan. Program yang akan digunakan akan berusaha merespon perilaku generasi millennial terhadap movie-going experience dan mengaplikasikannya dalam respon desain arsitektur.

Sementara riset kedua dilakukan ole Movio pada tahun 2016 dan berjudul Understanding Millennials Movie-Goers. Hasil utamanya berupa preferensi genre generasi milenial yang tergambar dalam diagram warna berikut :

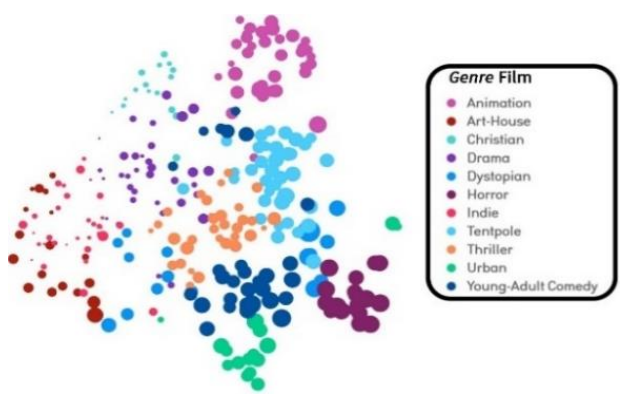

Gambar 5. Diagram Preferensi Genre Generasi Milenial

Sumber : Diolah oleh Penulis berdasarkan Movio, 2016 
Diagram di atas menginformasikan preferensi genre generasi milenial yaitu film-film franchise dan film-film animasi. Penulis juga telah melakukan wawancara singkat dengan Silvi Lim, founder dari Studio Mune, dan Fabian Loing, founder dari Studio Lumine. Secara keseluruhan, mereka berpendapat bahwa teknologi yang tersedia di Indonesia sesungguhnya sudah mampu mem-fasilitasi karya animasi local untuk bersaing dengan karya-karya internasional. Yang masih perlu ditingkatkan adalah konsep-tualitas dari karya animasi Indonesia. Edukasi yang diberikan masih cenderung terlalu fokus pada teknologi dibandingkan content dari sebuah cerita. Hal tersebut dan didukung pula oleh peningkatan preferensi generasi milenial terhadap film-film animasi adalah faktor utama yang melatarbelakangi pembangunan Animation Course pada proyek ini, yaitu untuk meningkatkan kemampuan pihak-pihak yang ingin menutut ilmu di bidang animasi akan konsep yang kuat, sehingga dapat berdampak pada hasil yang baik dan mampu bersaing dengan karya-karya serupa dari luar negeri.

\section{Tujuan}

Berdasarkan latar belakang perencanaan proyek dan identifikasi masala yang telah dipaparkan diatas, proyek CineFLicks : Movie Theater \& Animation Course memiliki 3 tujuan utama, antara lain :

- Merespon tuntutan generasi millennial akan inovasi baru dalam movie-going experience

- Mengembalikan popularitas hiburan bioskop dalam generasi millennial untuk mengimbangi kemajuan teknologi dan kesempatan kerja di bidang perfilman dan animasi

- Mengedukasi generasi millennial dalam bidang animasi (terutama 3D Modelling dan 3D Animation), serta meningkatkan konseptualitas karya-karya animasi yang dihasilkan

\section{Usulan Program}

Program-program usulan pada proyek yang bersangkutan berangkat dari 2 isu utama yang telah diuraikan di atas dan tujuan yang ingin dicapai perancang. Isu pertama adalah penurunan minat generasi milenial terhadap dunia perfilman, yang sesungguhnya memiliki signifikansi besar dalam segi hiburan dan edukasi, yang disebabkan karena tidak adanya inovasi baru dari hiburan bioskop dalam 20 tahun terakhir, namun diiringi kenaikan harga tiket 2 kali lipat. Dari isu ini, muncul usulan program pertama, yaitu Movie Theater yang dirancang untuk memenuhi ekspektasi dari generasi milenial akan hiburan perfilman yang inovatif.

Isu kedua adalah kebutuhan peningkatan konseptualitas dalam karya-karya animasi di Indonesia. Dari isu ini, muncul usulan program kedua, yaitu Kursus Animasi dengan programprogram pembelajaran yang disesuaikan dengan karakteristik target, yaitu generasi milenial.

\section{KAJIAN LITERATUR}

\section{Generasi Milenial}

Generasi milenial adalah mereka yang lahir antar tahun 1981-2000. Generasi millennial bervariasi secara sosial dan ekonomi. Namun, secara general mereka dipandang sebagai generasi yang familiar terhadap komunikasi, sosial media, dan teknologi digital. Generasi milenial menjadi topik penting dalam diskusi dekade ini karena jumlah populasi usia produktif memiliki jumlah tertinggi secara global hingga saat ini, 33\% lebih banyak dari generasi $X$. Generasi ini juga memiliki tingkat pendidikan tertinggi dibanding generasi lainnya, dan memiliki signifikansi besar serta dapat membawa perubahan terhadap dunia, termasuk tipologi dan lingkung bangun.

Generasi milenial memiliki beberapa karakteristik utama, antara lain cenderung percaya diri, lebih tertarik dalam bekerja berkelompok, memiliki ambisi besar dan memanfaatkan waktu untuk hal-hal yang diprioritaskan, mengutamakan dampak sosial yang dihasilkan dari pekerjaannya, dapat berinteraksi dengan teknologi secara intens (digitally native), cenderung lebih mementingkan experience dibanding possession, cenderung open-minded. 


\section{Ketentuan/Standar Dalam Perancangan Bioskop}

a. Kesesuaian Volume Ruang dengan Jumlah Penonton

\begin{tabular}{|c|c|c|c|}
\hline \multirow[b]{2}{*}{ Jenis auditorium } & \multicolumn{3}{|c|}{$\begin{array}{l}\text { Volume per tempat duduk } \\
\text { penonton, cu ft (cu m) }\end{array}$} \\
\hline & Min. & Opt. & Maks. \\
\hline Ruang pidato & $\begin{array}{l}80 \\
(2,3)\end{array}$ & $\begin{array}{l}110 \\
(3,1)\end{array}$ & $\begin{array}{l}150 \\
(4,3)\end{array}$ \\
\hline Ruang konser & $\begin{array}{l}220 \\
(6,2)\end{array}$ & $\begin{array}{l}275 \\
(7,8)\end{array}$ & $\begin{array}{l}380 \\
(10,8)\end{array}$ \\
\hline Rumah opera & $\begin{array}{l}160 \\
(4,5)\end{array}$ & $\begin{array}{l}200 \\
(5,7)\end{array}$ & $\begin{array}{l}260 \\
(7,4)\end{array}$ \\
\hline Gereja Roma Katolik & $\begin{array}{l}200 \\
(5,7)\end{array}$ & $\begin{array}{l}300 \\
(8,5)\end{array}$ & $\begin{array}{l}425 \\
(12)\end{array}$ \\
\hline Gereja Protestant dan tempat ibadah & $\begin{array}{l}180 \\
(5,1)\end{array}$ & $\begin{array}{l}255 \\
(7,2)\end{array}$ & $\begin{array}{l}320 \\
(9,1)\end{array}$ \\
\hline Auditorium serba-guna & $\begin{array}{r}180 \\
(5,1) \\
\end{array}$ & $\begin{array}{r}250 \\
(7,1) \\
\end{array}$ & $\begin{array}{c}300 \\
(8,5) \\
\end{array}$ \\
\hline Gedung bioskop & $\begin{array}{l}100 \\
(2,8)\end{array}$ & $\begin{array}{l}125 \\
(3,5)\end{array}$ & $\begin{array}{l}180 \\
(5,1)\end{array}$ \\
\hline
\end{tabular}

Gambar 6. Standar Volume Ruang per Jumlah Penonton

Sumber : Doelle, $1990: 58$

Standar volume ruang bioskop per penonton :

Minimal $2.8 \mathrm{~m}^{3}$ / orang, optimal $3.5 \mathrm{~m}^{3}$ / orang, dan maksimum $5.1 \mathrm{~m}^{3} /$ orang

b. Elemen Pembatas Ruang

Dinding : Dibuat anti gema suara dengan sistem "accoustic" dengan tujuan :

- mencegah gema suara yang memantul dan menggaduhkan bunyi asli

- mencegah penyerapan suara (absorpsi) sehingga suara hilang dan menjadi kurang jelas

- membantu resonansi (menguatkan suara)

Lantai

- Lantai dibuat dari bahan yang kedap air, keras, tidak licin dan mudah dibersihkan.

- Kemiringan dibuat sedemikian rupa sehingga pemandangan penonton yang dibelakang tidak terganggu oleh penonton yang dimuka.

Menurut hasil penyelidikan yang dilakukan oleh Departemen Penerangan bersama Lembaga IImu Pengetahuan Indonesia (LIPI) menyatakan bahwa : Jarak antara sandaran kursi adalah $90 \mathrm{~cm}$, dengan sudut penurunan ideal ke arah layar 6,28 terhadap garis horizontal, berarti perbedaan tinggi kepala kursi yang berurutan $10 \mathrm{~cm}$.

c. Penataan Layout Bioskop, Pemiringan Area Penonton dan Peninggian layar

Area sirkulasi yang terletak di tengah sebaiknya dialihkan ke sisi kiri dan kanan ruang, sehingga bagian tengah dapat dioptimalkan sebagai area duduk penonton, karena merupakan posisi terbaik secara akustik dan visual. Namun, jarak antar baris penonton perlu cukup lebar untuk memudahkan akses.

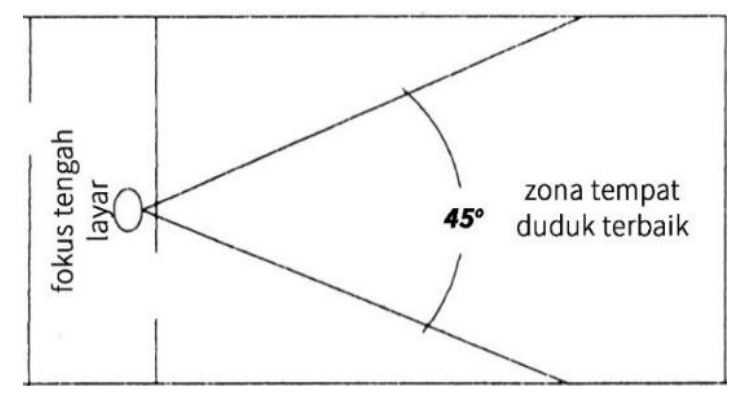

Gambar 7. Zona Optimal Tempat Duduk secara Akustik dan View Sumber : Doelle, $1990: 57$ 


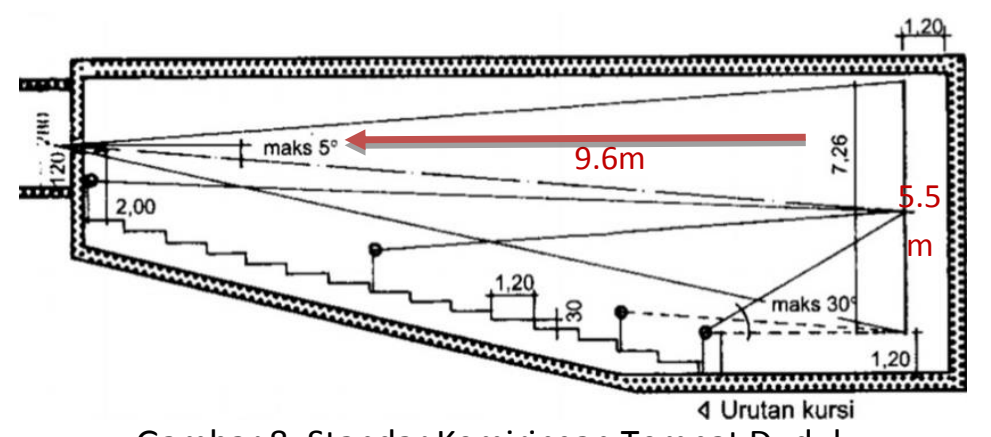

Gambar 8. Standar Kemiringan Tempat Duduk

Sumber : Data Arsitek, Edisi 33. Jilid 2: 146

- Ketinggian layar total $=8.6+1.2=9.8 \mathrm{~m}$

- Ketinggian mata penonton terdepan saat duduk dengan derajat max $30^{\circ}$ ke titik tengah layar $=\mathbf{1 . 4 2} \mathrm{m}$

- Tinggi jatuh mata penonton $=1.2+(8.6 / 2)=5.5 \mathrm{~m}$

- Makan jarak horizontal penonton terdepan dari layar $=\mathbf{9 . 6} \mathbf{m}$

d. Layar: Berwarna putih dengan warna gelap ditepi, Jarak ideal layar dengan proyektor $\pm 40 \mathrm{~m}$

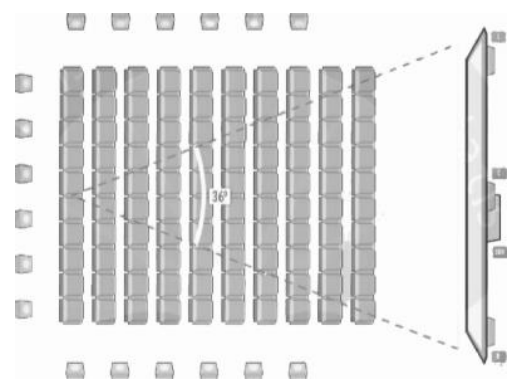

Gambar 9. Standar Kursi Terjauh dan Terdekat

Sumber : www.thx.com/certified-cinema/

- Perhitungan titik mata terjauh $=36^{\circ}$

- Kebutuhan ruang yang didapat dari perbandingan proyektor dan besar bentang layar, didapat jarak mata terjauh $=30.5 \mathrm{~m}$.

- Penataan kursi pada bagian depan dipengaruhi oleh jangkauan besar sudut manusia dapat melihat dengan jelas, yaitu 120 o. Oleh karena itu, sebaiknya kursi pada bagian kiri dan kanan depan beberapa ditiadakan demi mengoptimalkan kenyamanan mata penonton.

e. Proyektor Film dan Ruangan

- Sebaiknya ada 2 buah proyektor sehingga tidak ada jeda saat pergantian antar rol film, harus baik, tidak bergetar, dan terang sehingga tidak merusak mata

- Ruang untuk proyektor disesuaikan dengan ukuran proyektor dan jumlah petugas

- Kelembaban \& suhu yang diperhatikan

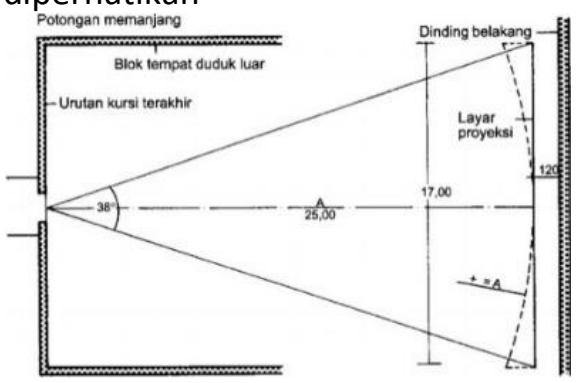

Gambar 10. Standar Jarak Proyektor

Sumber : Data Arsitek, Edisi 33. Jilid 2: 146 
Standar besar sudut pemancaran pro-yektor adalah $38^{\circ}$, dan stan-dar lebar screen adalah $20.1 \mathrm{~m}$, sudut $38^{\circ}$ yang dihasilkan proyektor akan tepat ditang-kap layar sebesar $20.1 \mathrm{~m}$ dengan jarak $30 \mathrm{~m}$. Sehingga berdasarkan standar ini, didapat minimal dimensi luas $23 \times 30 \mathrm{~m}$ $=690 \mathrm{~m}^{2}$

\section{f. Sound System --- PRINSIP : Absorbsi Sebanyak Mungkin}

Sound system adalah suatu alat elektronikyang digunakan untuk mengeraskan suarasehingga bisa terdengar jelas oleh seluruhpenonton. Sound system yang baik digunakan di gedung bioskop adalah sound system stereo dengan peletakan pengeras suara pada dinding dalam jarak yang sama antara yang satu dengan yang lain, sehingga suara akan diterima merata oleh penonton.

Absorpsi merupakan hal terpenting dalam objektif perancangan sebuah bioskop. Berbeda dengan gedung konser di mana suara harus dipantulkan sebanyak mungkin. Gedung bioskop harus menyerap suara sebanyak mungkin dan memantulkan suara seminimal mungkin karena berpotensi menghasilkan gaung. Penyerapan suara biasanya disiasati dengan pemasangan material dengan permukaan lembut dan lunak, seperti penggunaan busa, gabus, styrofoam, spons, kain dan karpet pada dinding samping kiri dan kanan, serta dinding belakang. Pada saat gelombang bunyi mengenai permukaan lemut dan lunak, gelombang bunyi tidak dipantulkan, namun diserap sebagai energi panas. Akibatnya tidak ada gaung yang terjadi. Proses mengurangi gaung dan gangguan akibat pemantulan gelombang bunyi ini disebut dengan "soundproofing," dan banyak digunakan pada ruangan yang memerlukan bunyi dan suara yang jernih, seperti bioskop, concert hall, recording studio, dan opera. Selain itu, bahan kursi harus dipilih yang tidak menyerap suara, tetapi tetap membuat penonton nyaman. Prinsipnya, dalam keadaan kosong ataupun diduduki, diusahakan agar tingkat penyerapan suara sama.

Waktu dengung adalah rentang waktu antara saat bunyi terdengar hinggamelenyap. Gedung bioskop dianggap baik ketikamemiliki waktu dengung sekitar 1,1 detik.

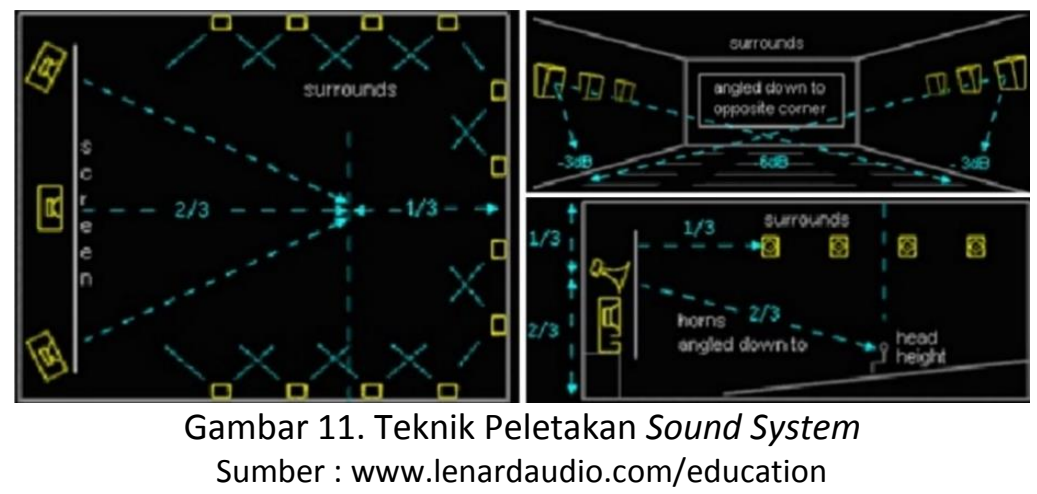

Prinsip peletakan speaker yang digunakan untuk menghasilkan aliran suara yang konsisten di semua tempat dalam bioskop tergambar dalam diagram diatas. Speaker yang ada di belakang layar diletakkan mengarah ke bagian ruangan yang terletak $2 / 3$ kedalaman ruangan. Sedangkan tinggi speaker berada di $1 / 3$ dari tinggi ruangan. Surround speaker terdekat dari layar, minimal berjarak $1 / 3$ kedalaman ruangan.

\section{g. Air Conditioning}

AC yang baik untuk gedung bioskop adalah menggunakan AC central. Prinsip kerjanya adalah penyaringan, pendinginan, pengaturan kelembaban serta pengaturan suhu dalam ruangan. Suhu ruang yang baik : antara $20^{\circ} \mathrm{C}-25^{\circ} \mathrm{C}$, dengan kelembaban diantara $40 \%-50 \%$ (Rudi Gunawan, 2008). 
h. Tempat Duduk Penonton

- Ada sandaran belakang dan sandaran tangan yang sekaligus berfungsi pembatas,

- Jarak dengan tempat duduk depannya $40 \mathrm{~cm}$ (berfungsi sebagai jalan pengunjung),

- Baris terdepan min $6 \mathrm{~m}$ darilayar, dengan sudut pandang $<30$,

- Penonton yangduduk di baris terdepan harus masih dapatmelihat seluruh gambar sepenuhnya. Artinyabagian tepi layar atas, bawah dan samping kiridan kanan berturutturut maksimummembentuk sudut 60-80 dengan titik mata.

- Tinggi tempat duduk dan lantai sebaiknya $48 \mathrm{~cm}$ dengan sandaran $38-40 \mathrm{~cm}$,

- Tempat duduk dibuat empuk namun tidak bersifat absorbtif.

i. Pintu Darurat

- Lebar minimal pintu darurat adalah 2 kali lebar pintu biasa $(160 \mathrm{~cm})$

- Jarak pintu darurat yang satu dengan lain sedikit-dikitnya $5 \mathrm{~m}$ dengan tinggi 1,8 dan membuka kearah ke luar

- Letak pintu darurat sebelah kiri dan sebelah kanan ruang pertunjukkan harus simetris

- Selama pertunjukan berlangsung pintu darurat tidak boleh di kunci

- Di atas pintu harus dipasang lampu merah dengan tulisan yang jelas "Pintu Darurat".

j. Pemadam Kebakaran: Perlu disediakan di dlm gedung pertunjukan, Diletakkan terpencar, mudah dilihat, mudah dicapai, Perlu disertai petunjuk cara penggunaan

k. Sistem Lalu Lintas dalam Gedung (traffic system): Lalu lintas utama (4m), Lintas block (80 $\mathrm{cm})$, Lintas antar kursi $(40 \mathrm{~cm})$.

\section{Jangkauan Pengelihatan Manusia}

Diagram di bawah ini menunjukkan batasan-batasan posisi tempat duduk penonton secara horizontal dan vertikal yang masih memenuhi standar kenyamanan horizontal field of view mata manusia.

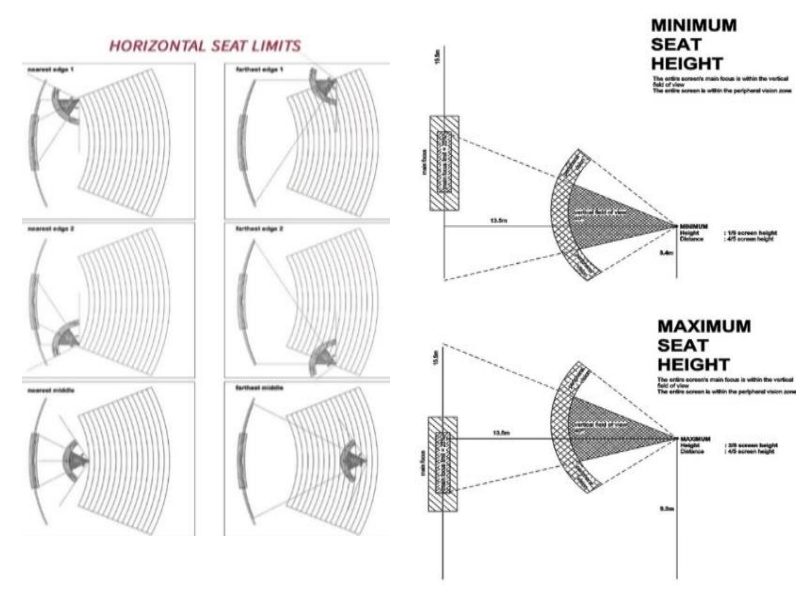

Gambar 12. Jangkauan pengelihatan manusia (vertikal dan horizontal) Sumber : Penulis, 2019

\section{METODE}

Metode yang digunakan adalah metode tipologi. Tipologi adalah kajian tentang tipe. Dalam dunia arsitektural, tipe berarti klasifikasi sistematik berdasarkan karakter fisik. Salah satu tujuan utama dalam proyek CineFlicks : Bioskop \& Kursus Animasi adalah memberikan inovasi terbaru dalam motion picture entertainment. Dengan penggunaan metode tipologi, penulis berharap dapat memahami perkembangan movie theater dari awal terbentuknya hingga sekarang, mempelajari aspek apa saja yang mengalami perubahan dan aspek apa saja yang 
tetap diterapkan serta alasan-alasannya. Dengan itu, penulis berharap dapat meng-hasilkan desain yang sesuai dengan kebutuhan generasi milenial dan mampu memenuhi tujuan utama dari proyek yang bersangkutan, yaitu untuk mengembalikan esensi dari motion picture entertainment bagi kaum milenial.

Berikut adalah panel studi tipologi yang telah dilakukan penulis terhadap bangunan movie theater dari awal terbentuknya hingga saat ini.

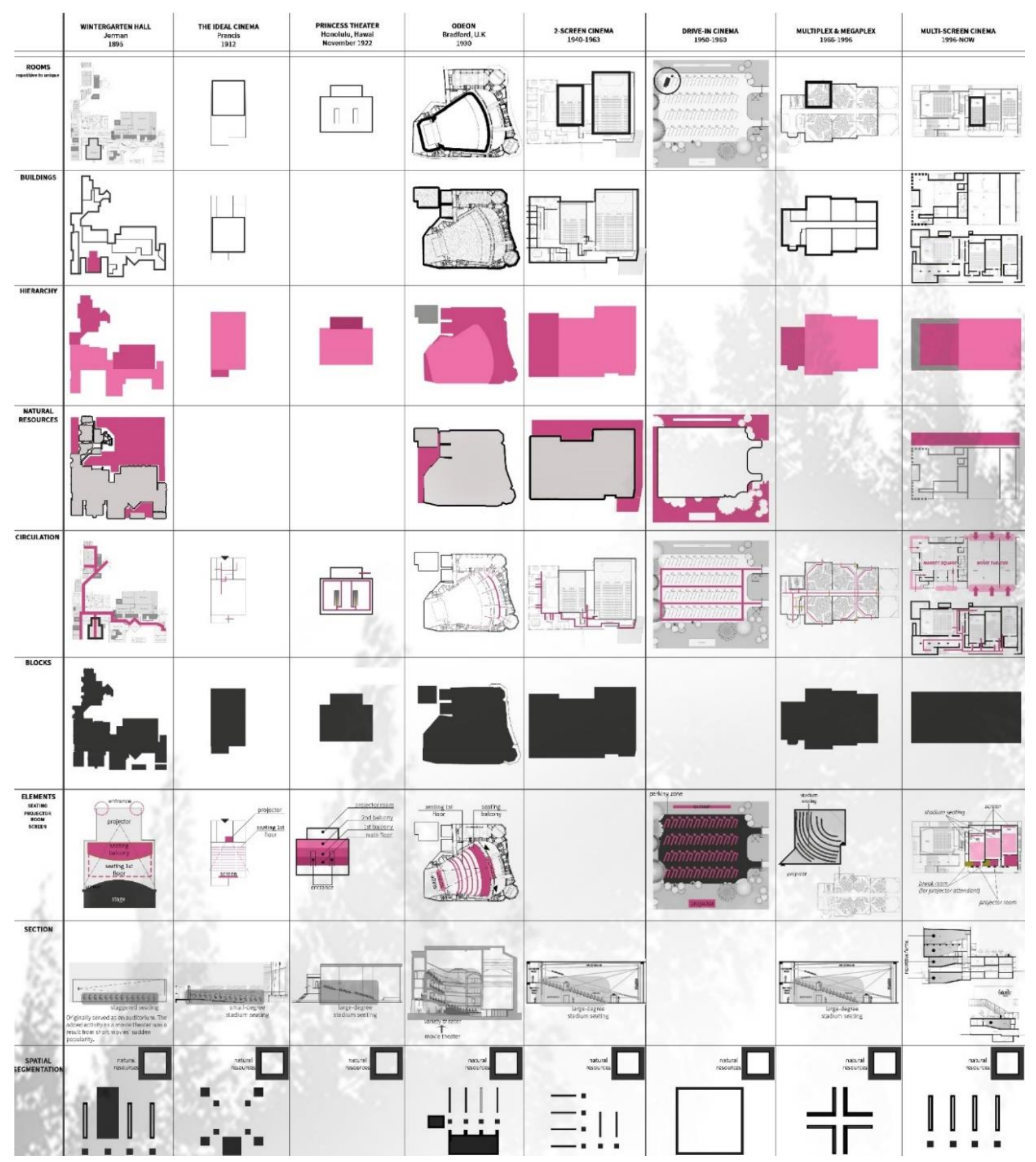

Gambar 13. Panel Studi Tipologi

Sumber : Penulis, 2019

\section{DISKUSI DAN HASIL}

\section{Penerapan Tipologi Bioskop Dalam Desain}

Penulis menyimpulkan bahwa tipologi bioskop dari awal terbentuknya pada tahun 1895 hingga saat ini mengalami 8 tahap perubahan besar. Awalnya, movie theater hanya merupakan sebuah studio di bangunan komersial yang berkapasitas sekitar 60-100 orang. Kemudian, seiring dengan kemajuan hiburan perfilman, dibuat bangunan khusus untuk menyaksikan film 
yang terdiri dari 1 studio. Di perkembangan selanjutnya, movie theater menjadi sebuah fungsi tambahan pada bangunan skala besar yang berfungsi utama sebagai ruang orkestra atau opera. Lalu, mulai muncul bioskop dengan lebih dari 1 studio, hingga akhirnya muncul megaplex, dimana 1 bioskop dapat terdiri dari 10-20 studio. Pada perkembangan terakhir, penulis dapat melihat kembalinya movie theater ke tipologi yang berkembang pada tahun 1940-1963, dimana bioskop hanya terdiri dari 2-5 studio. Berdasarkan data-data dan analisa yang telah dilakukan, dapat disimpulkan bahwa alasan tipologi ini muncul kembali antara lain adalah ekspektasi generasi milenial, sebagai target audience utama bioskop yang tinggi terkait dunia perfilman. Semakin sedikit film-film yang dipandang worth-it untuk disaksikan di bioskop, terutama dengan kesibukan yang meningkat. Selain itu, didukung pula dengan biaya operasional tinggi dan munculnya studio-studio film yang mampu menampung banyak orang, seperti IMAX, yang berkapasitas hingga 450 orang.

Tipologi yang digunakan dalam proyek mengkombinasikan tipologi yang berkembang di era milenial, yaitu bangunan dengan fungsi utama sebagai bioskop yang terdiri dari 2-5 stu-dio film, dan tipologi yang berkembang pada tahun 1930, dimana sebuah bangunan yang diperuntukkan sebagai tempat menyaksikan film dapat menampung audience berjumlah besar. Pemilihan tipologi ini berdasar pada pertimbangan bahwa generasi milenial, sebagai target audience utama bioskop memiliki ekspektasi yang tinggi terkait dunia perfilman. Semakin sedikit film-film yang dipandang worth-it untuk disaksikan di bioskop, terutama dengan kesibukan yang meningkat. Pada proyek yang bersangkutan, perancang berupaya menghadirkan inovasi-inovasi baru, baik dari segi arsitektur dan teknologi untuk meningkatkan minat generasi milenial terhadap motion picture entertainment yang sesungguhnya memiliki signifikansi besar sebagai hiburan, edukasi, dan passion mereka.

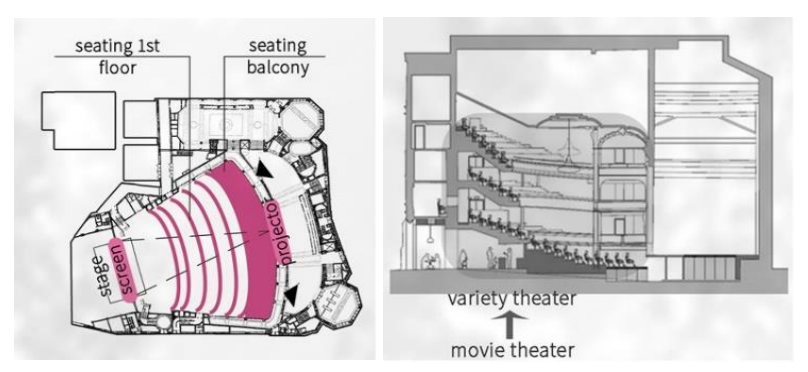

Gambar 14. Tipologi yang Digunakan dalam Proyek Sumber : Penulis, 2019

Gambar di atas merupakan contoh tipologi movie theater yang berkembang pada tahun 1930. Penataan tempat duduk audience mengikuti bangunan konser opera dan orkestra yang lengkung untuk memaksimalkan kualitas visual yang didapat audience pada berbagai titik dalam ruangan. Perbedaan ketinggian antar baris tempat duduk sekitar $37 \mathrm{~cm}$ sebagai upaya memaksimalkan pandangan ke panggung secara vertikal.

Movie Theater yang dirancang terdiri dari 2 studio yang masing-masing berkapasitas 380 orang. Bangunan dilengkapi dengan berbagai fasilitas terkait dengan hiburan perfilman, seperti area merchandising, photo booths, dan seni-seni instalasi dengan tema sesuai film yang sedang tayang. Area interactive animation experience bertujuan memberikan gamba-ran pada pengunjung mengenai teknik-teknik pembuatan film animasi, sebagai genre yang mengalami peningkatan pesat sebagai preferensi generasi milenial dalam 5 tahun terakhir.

\section{Konsep Desain Bioskop}

Movie Theater yang dibuat berupaya memberikan sebuah cinematic experience yang baru, dengan memposisikan penonton sedekat mungkin dengan layar namun tetap memperhatikan kenyamanan jangkauan pengelihatan secara vertikal dan horizontal, dan mengekspansi layar hingga ke batas pengelihatan periferal, yang merupakan trigger utama manusia yang menimbulkan kesan motion. 
Dalam pewujudan sebuah inovasi desain pada proyek movie theater, penulis mengkom-binasikan analisa batasan-batasan posisi tempat duduk terhadap layar secara horizontal dan vertical seperti pada gambar $6,7,8$, dan 9 dengan jenis penataan tempat duduk dari tipologi yang terpilih, seperti pada gambar 17. Penataan tempat duduk yang terbentuk akan cende-rung meluas secara vertikal, dengan perbedaan ketinggian antar baris $90 \mathrm{~cm}$ dan terdiri dari 3 lantai, sebagai upaya optimalisasi pengelihatan periferal audience terhadap layar secara horizontal dan vertikal. Diagram di bawah ini merupakan skematik desain movie theater yang akan dibuat, sebagai kombinasi dari analisa batasan jangkauan pandang manusia dengan jenis penataan tempat duduk tipologi terpilih.
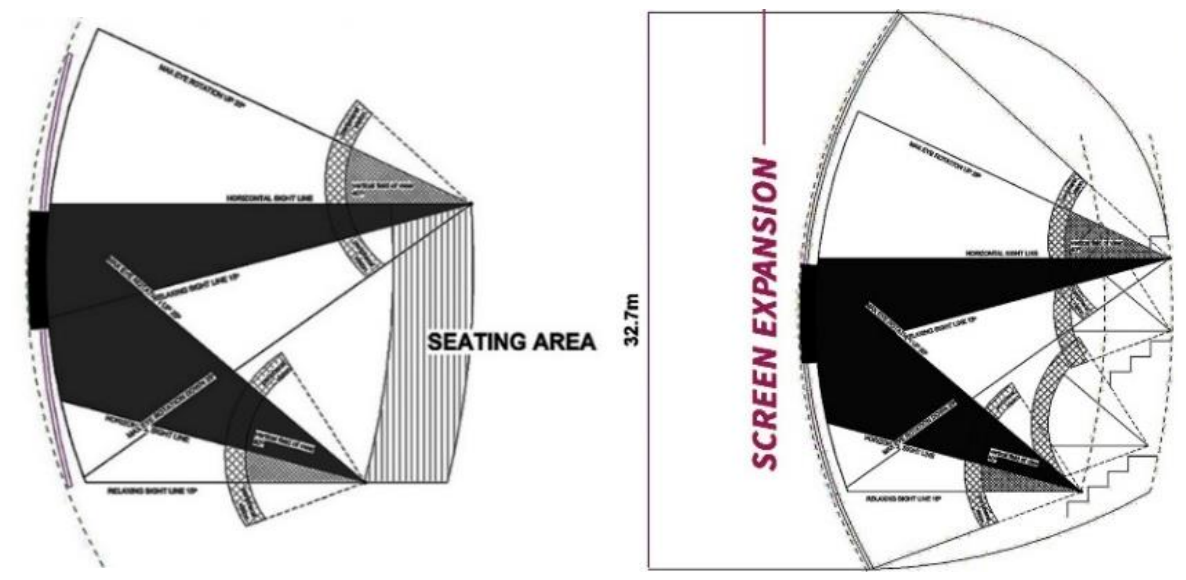

Gambar 15. Seating Area yang terbentuk dan Peletakan Tempat Duduk pada Desain Sumber : Penulis, 2019

\section{Proses Desain}
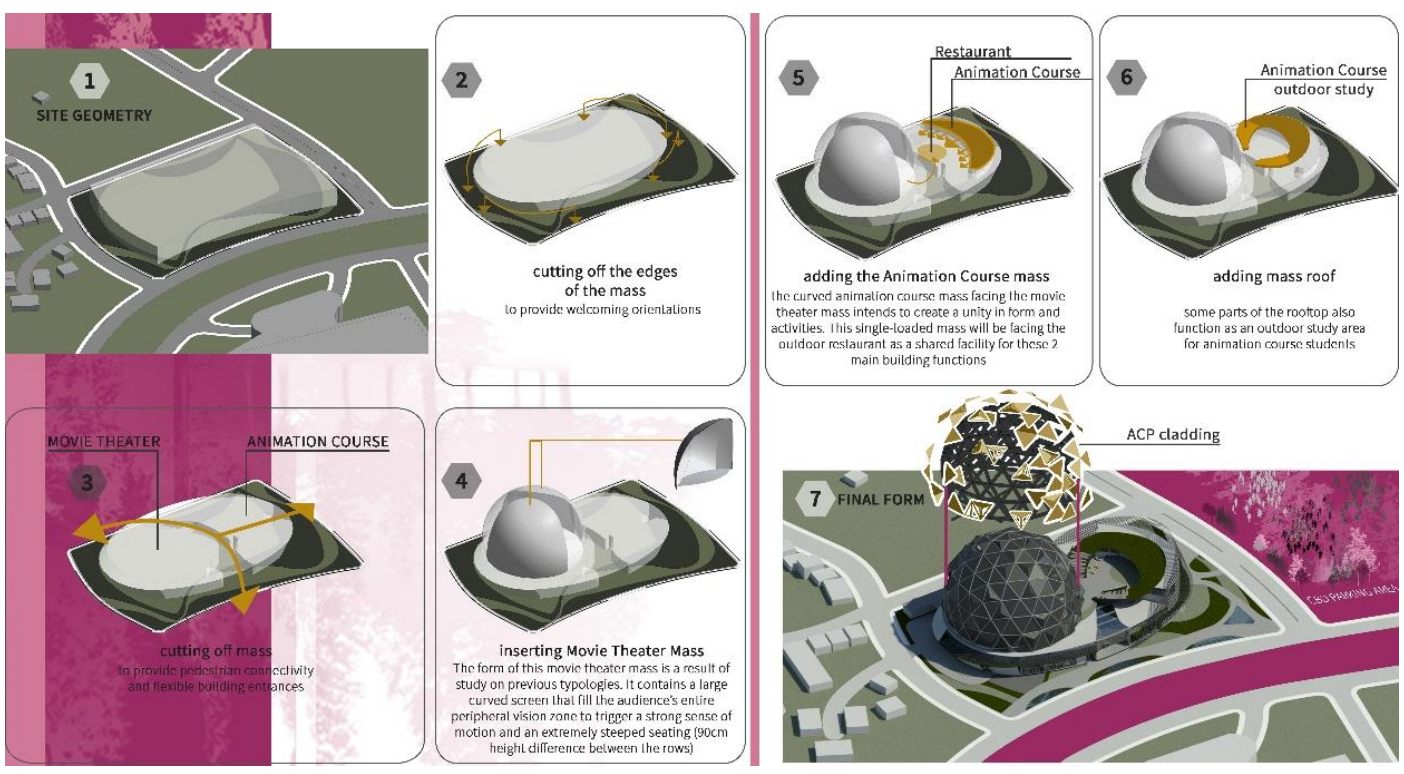

Gambar 16. Diagram Proses Desain

Sumber : Penulis, 2019 


\section{Inovasi Desain Baru Bioskop}

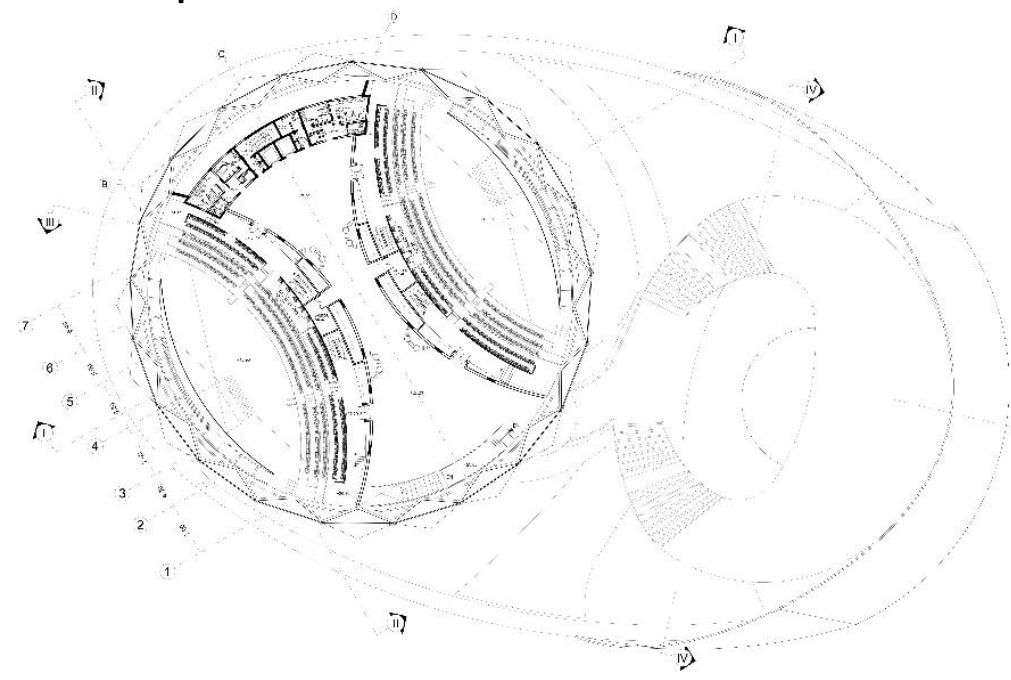

Gambar 17. Denah Bangunan Lantai 6

Sumber : Penulis, 2019

Gambar di samping adalah denah bangunan lantai teratas, yang menunjukkan bentuk kelengkungan tempat duduk audience dan peletakan kedua movie theater pada bangunan. Layar menempel pada kulit dome bangunan yang terekspansi secara horizontal dan vertikal ke batas pengelihatan periferal manusia.

Gambar-gambar di bawah ini menunjukkan potongan bangunan. Movie theater terletak pada lantai 4, 5, dan 6 dan masing-masing teater memiliki total kapasitas 380 orang. Layar memiliki ketinggian 22 meter, sekitar 4 kali lipat lebih besar dari layar bioskop konvensional.

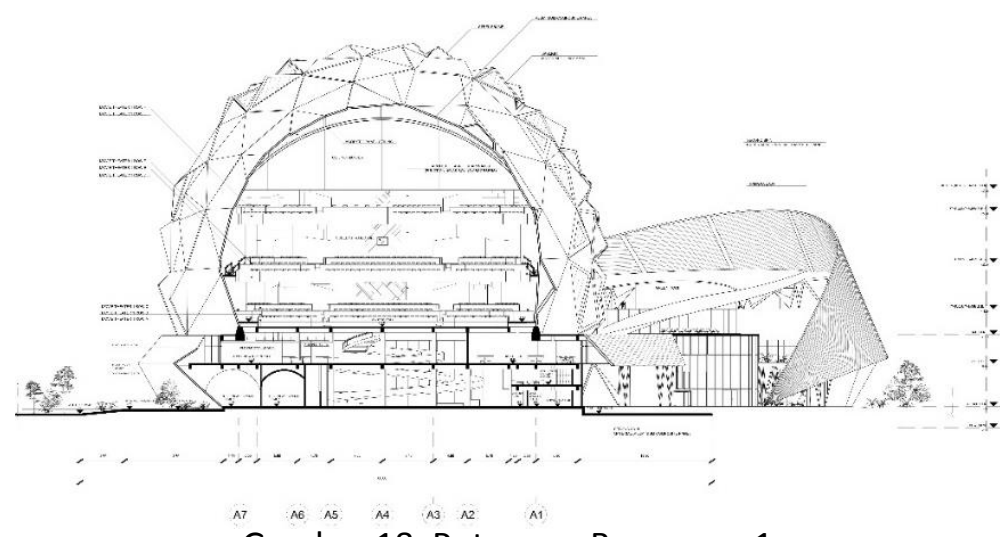

Gambar 18. Potongan Bangunan 1

Sumber : Penulis, 2019

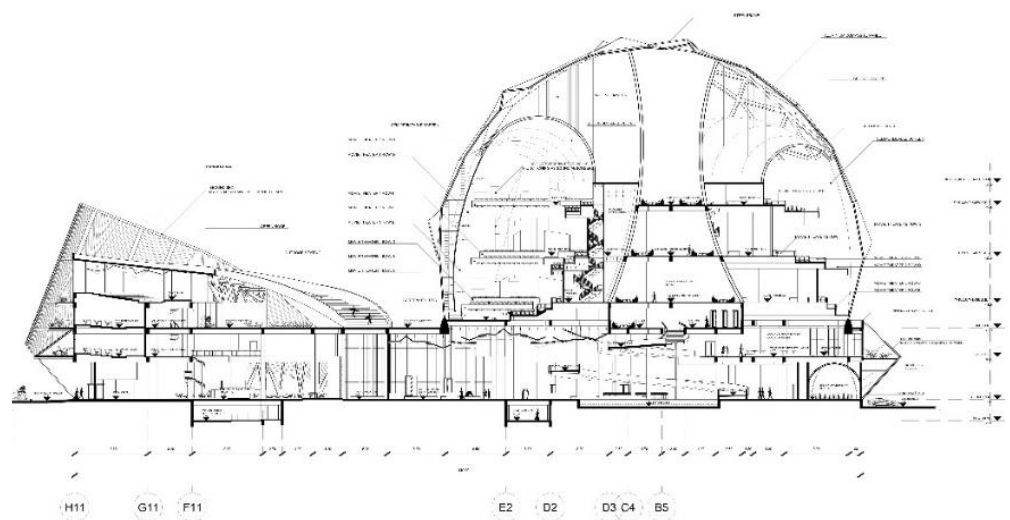

Gambar 19. Potongan Bangunan 2

Sumber : Penulis, 2019 
Gambar di bawah ini merupakan gambaran desain keseluruhan :

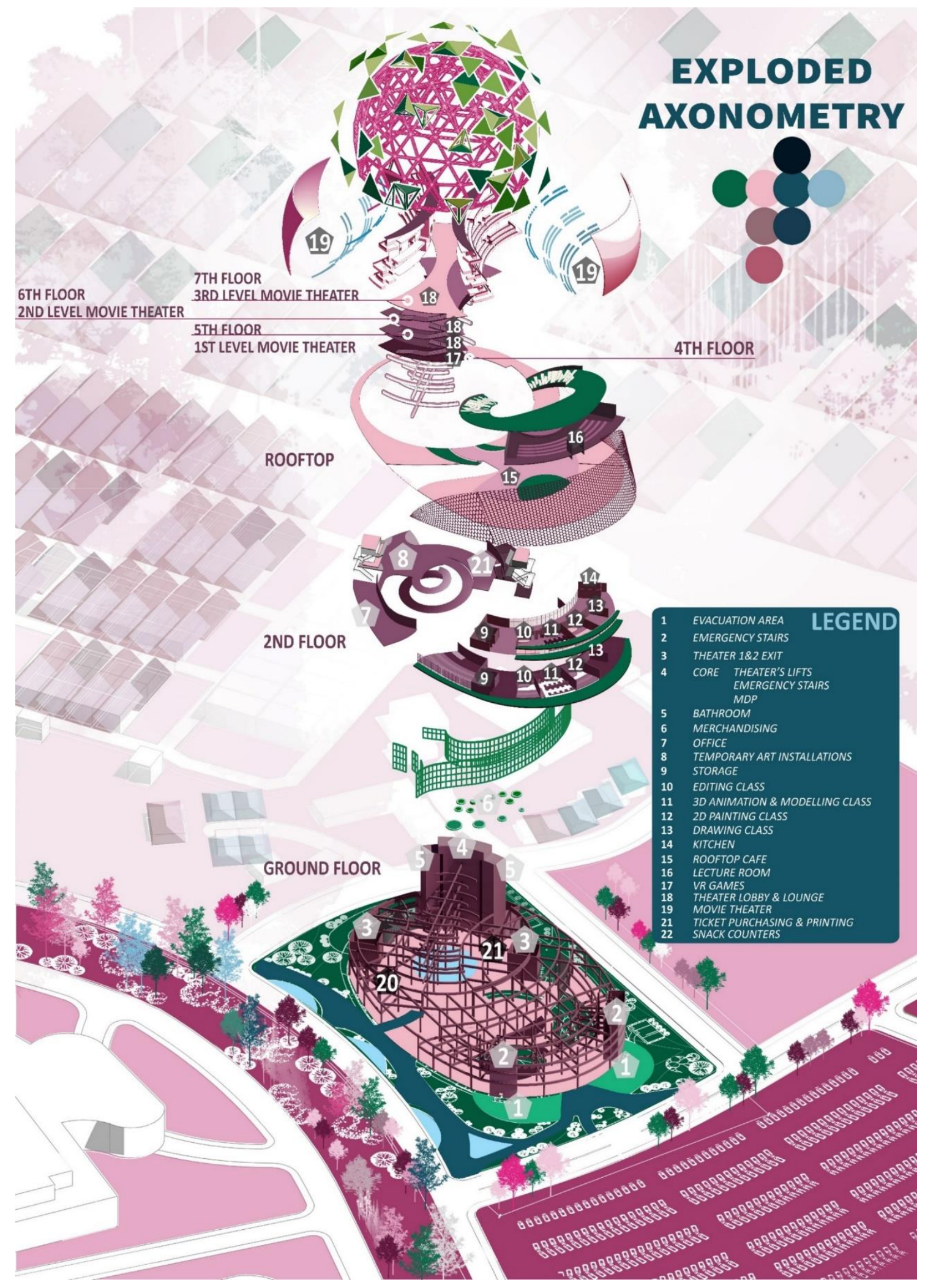

Gambar 20. Exploded Axonometry Bangunan

Sumber : Penulis, 2019 


\section{KESIMPULAN DAN SARAN \\ Kesimpulan}

Perbedaan karakteristik dan gaya hidup generasi milenial menimbulkan masalah-masalah dan trend baru di milenial era. Proyek CineFlicks : Bioskop \& Kursus Animasi" yang berlokasi di Jalan BSD Grand Boulevard, Kabupaten Tangerang memiliki 2 tujuan utama, antara lain mengembalikan esensi dari motion picture entertainment bagi generasi milenial dengan memperbarui cinematic experience dan movie theater venue, serta meningkat-kan kualitas serta konseptualitas karya-karya film dan animasi oleh kreator Indonesia. Program-program utama dalam proyek antara lain adalah movie theater, pelatihan animasi, ruang seminar, dan motion picture history gallery, yang masing-masing merespon millennials' movie-going behaviours dan berperan dalam pencapaian tujuan-tujuan utama proyek. Pembangunan proyek "CineFlicks : Bioskop \& Kursus Animasi" di lokasi yang bersangkutan diharapkan dapat memberikan profit bagi lokasi tersebut dan juga membantu pencapaian tujuan proyek itu sendiri, yaitu sebagai pusat movie entertainment dan penyedia edukasi animasi.

\section{Saran}

Saran penulis bagi motion picture entertainment ke depannya adalah untuk lebih memperha-tikan tuntutan generasi milenial akan inovasi-inovasi baru pada hiburan perfilman, baik dari segi cinematic experience dan fasilitas-fasilitas penunjuang lainnya. Terkait dengan proyek yang bersangkutan, pengembangan lebih dapat difokuskan pada pemanfaatan area lobby teater yang cenderung kosong untuk area seni-seni instalasi. Selain itu juga pengembangan penataan tempat duduk untuk kelas-kelas kursus animasi agar lebih fleksibel.

\section{REFERENSI}

Doelle, L. (1990). Akustik lingkungan. Jakarta: Erlangga.

Kuttruff, H. (1979). Room Accoustics. London: Spon Press 11 New Fetter Lane.

Mediastika, C.E. (2005). Akustika bangunan. Jakarta: Erlangga.

Neufert, E. (2002). Data Arsitek. Edisi 2. Jakarta: Erlangga.

Roderick, H. (1987). Theater Planning. Architectural Press.

Discover the Advantage in

Design,<Http://www.acoustics.com/product_page.asp?prod_id=63>

<Http://fariable.blogspot.com/2011/08/spesifikasi-ruang-pertunjukan-teori.html >

$<$ Http://www.scribd.com/doc/57719313/akustik-bangunan >

$<$ Http://www.rpginc.com/product_Absorbor_Panels.cfm>

$<$ Https://allgroanup.com/twentysomething-life-2/5-shocking-statistics-about-the-challenges-

facing-the-millennial-generation-and-how-we-overcome/>

$<$ Https://medium.com/ipg-media-lab/the-future-of-movie-going-cd935c2a954c>

$<$ Https://www.annalect.com/annalect-research-now-showing-millennials-movie-going-

experience/>

$<$ Https://en.wikipedia.org/wiki/Movie_theater\#History>

$<$ Https://www.archdaily.com/115928/mellat-park-cineplex-fluid-motion-architects>

$<$ Http://www.esda.co.id/specialize/>

$<$ Http://archive-academy.hellomotion.com/program-belajar> 
